\title{
Analisis perbandingan algoritma Naïve Bayes, k-Nearest Neighbor dan Neural Network untuk permasalahan class-imbalanced data pada kasus credit card fraud dataset
}

\section{Comparative analysis of the Naïve Bayes, $k$-Nearest Neighbor and Neural Network algorithms for class-imbalanced data problems in the case of credit card fraud dataset}

\author{
Mita Yuanika Sahroni a, ${ }^{,}$, Niken Ayu Setifani ${ }^{b}$, Devinta Nurul Fitriana ${ }^{c}$ \\ $a, b, c$ Sistem Informasi, Universitas Islam Negeri Sunan Ampel Surabaya, Surabaya, Indonesia \\ email:a,"mitaysahroni@gmail.com, ${ }^{\circ}$ nikenayustef@gmail.com, ${ }^{c}$ devintafitriana28@gmail.com
} "Koresponden

\begin{tabular}{l}
\hline I N F O A R T I K E L \\
\hline Sejarah artikel: \\
Menerima 12 April 2021 \\
Revisi 5 Mei 2021 \\
Diterima 28 Mei 2021 \\
Online 25 Agustus 2021 \\
\hline
\end{tabular}

Kata kunci:

class-imbalanced data

classification tasks

credit card fraud dataset

undersampling

Neural Network

\section{Keywords:}

class-imbalanced data

classification tasks

credit card fraud dataset

undersampling

Neural Network

Style APA dalam menyitasi artikel ini:

Sahroni, M. Y., Setifani, N. A., \& Fitriana, D. N. (2021) Analisis perbandingan Algoritma Naïve Bayes, KNearest Neighbor Dan Neural Network untuk permasalahan classimbalanced data pada kasus credit card fraud dataset. Teknologi: Jurnal Ilmiah Sistem Informasi, 69-73.

\begin{abstract}
ABSTRAK
Tingginya animo masyarakat dalam bertransaksi menggunakan kartu kredit di sektor perbankan berpotensi meningkatkan penipuan kartu kredit (credit card fraud). Penelitian ini menggunakan credit card fraud dataset yang terdiri dari 284.807 data yang didapatkan dari Kaggle. Dataset pada penelitian ini bersifat class-imbalanced data dengan perbandingan antara kelas mayor sejumlah $99,8 \%$ dan kelas minor sejumlah $0,2 \%$. Permasalahan class-imbalanced data ini akan diselesaikan dengan menerapkan undersampling. Guna mengetahui kinerja algoritma klasifikasi yang paling cocok untuk mengatasi permasalahan classimbalanced data, maka akan dilakukan perbandingan algoritma Naïve Bayes, kNearest Neighbor (k-NN) dan Neural Network. T-test pada penelitian ini dilakukan guna mengetahui adanya signifikansi perbedaan antar algoritma. Evaluasi kinerja algoritma menggunakan nilai akurasi dan AUC (area under the curve). Hasil pengujian pada penelitian ini adalah Neural Network memiliki kinerja lebih baik dari pada algoritma lainnya karena memililiki nilai akurasi tertinggi sebesar 93,59\% dan nilai AUC 0,977. Berdasarkan hasil t-test, Neural Network dengan kNN memiliki perbedaan yang signifikan, berbeda dengan Neural Network dengan Naïve Bayes tidak ada perbedaan yang signifikan.
\end{abstract}

\section{ABSTRACT}

The high public interest in transactions using credit cards in the banking sector has the potential for higher credit card fraud. This study uses a credit card fraud dataset that consisting of 284,807 data obtained from Kaggle. The dataset in this study is classimbalanced data with a comparison between the major class of $99.8 \%$ and the minor class of $0.2 \%$. This class-imbalanced data problem will be solved by applying undersampling. In order to determine the performance of the classification algorithm that is most suitable for solving class-imbalanced data problems, a comparison of the Naïve Bayes, $k$-Nearest Neighbor ( $k N N)$ and Neural Network algorithms will be carried out. The t-test in this study was conducted to determine the significance of differences between algorithms. Algorithm performance evaluation uses accuracy and AUC (area under the curve) values. The test results in this study is Neural Network has better performance than other algorithms because it has the highest accuracy value of $93.59 \%$ and AUC value of 0.977 . Based on the t-test results, the Neural Network with $k$-NN has a significant difference, in contrast to the Neural Network with Naïve Bayes there is no significant difference.

Teknologi: Jurnal IImiah Sistem Informasi dengan lisensi CC BY NC SA

\section{Pendahuluan}


Kegiatan transaksi keuangan yang dilakukan oleh masyarakat merupakan sebuah kegiatan dalam dunia perbankan. Dalam suatu proses perjanjian dapat terjadi banyak kemungkinan salah satunya adalah tindakan fraud. Fraud merupakan suatu tindakan menyimpang atau suatu perbuatan yang melanggar hukum (illegal act) yang dapat dilakukan dengan sengaja untuk suatu tujuan tertentu seperti melakukan penipuan atau memberikan sebuah gambaran yang keliru (mislead) kepada pihak lain yang dilakukan oleh pihak dalam atau luar organisasi tersebut (Karyono, 2013). Seluruh jenis transaksi harus tercatat pada laporan keuangan bank tersebut yang akan digunakan sebagai bentuk pertanggungjawaban manajemen bank kepada pihak terkait. Kecurangan dalam laporan yang disengaja, sehingga terjadi turunnya pendapatan yang diterima oleh bank. Perusahaan yang berkemungkinan besar akan lebih sering mengalami tindakan fraud adalah pada bidang keuangan atau perbankan dibandingkan dengan perusahaan yang pada bidang lainnya.

Perkembangnya teknologi dan komunikasi secara global yang sangat cepat dan tinggi dapat mengakibatkan kemungkinan terjadinya kecurangan dalam bidang financial semakin meningkat (Zareapoor, Seeja, \& Alam, 2012). Peningkatan penggunaan kartu kredit terjadi peningkatan yang sangat besar dalam kredit penipuan kartu dalam beberapa tahun terakhir. Dengan adanya internet menjadikannya mudah untuk memberikan kredit secara otomatis kepada pelanggan. Kecurangan dalam transaksi kartu kredit ternyata menjadi masalah besar bagi bank. Pada bank, tindakan fraud dapat memberikan dampak yang sangat merugikan seperti kerugian dalam keuangan dan penurunan tingkat kepercayaan nasabah kepada bank tersebut. Suatu tindakan fraud bisa terjadi di manapun bidang pekerjaannya, bisa berada pada pihak internal maupun pihak eksternal. Pada bidang perbankan bagian internal dapat dilakukan oleh karyawan terjadi saat informasi suatu kartu kredit tertentu dari banyak individu dikumpulkan secara ilegal dan dapat digunakan untuk penipuan transaksi atau dengan memanipulasi data-data transaksi terkait rekam data kartu kredit (Khatri, Arora, \& Agrawal, 2020). Kemajuan Teknologi dan peningkatan transaksi online terutama pada kartu kredit mengakibatkan penipuan yang menyebabkan kerugian finansial yang sangat besar. Oleh karena itu, perlu adanya metode efektif untuk mengurangi kerugian (Shirodkar, et al., 2020). Pihak bank membutuhkan suatu upaya untuk mendeteksi dan melakukan pencegahan tindakan fraud dengan cepat dan akurat. Suatu upaya untuk melakukan penanganan fraud dengan cara mendeteksi kecurangan dapat dilakukan sebuah audit kecurangan atau fraud audit (Karni, 2000). Auditor akan menganalisis data yang dimiliki oleh perusahaan terutama pada data keuangan dengan melihat laporan akuntansi memiliki kesalahan atau sebuah keganjilan sehingga auditor dapat mengetahui bahwa laporan tersebut tidak dapat dipercaya.

Cara menyelesaikan imbalance data dibagi menjadi kategori level data dengan mengubah alur atau distribusi dataset dan level algoritma dengan memodifikasi algoritma yang akan digunakan (Shin \& Cho, 2006). Teknik klasifikasi merupakan salah satu solusi untuk mengetahui algoritma yang terbaik dalam credit card fraud dataset. Berdasarkan uraian di atas, penelitian ini akan dilakukan prediksi terhadap data credit card. Pada credit card fraud dataset terdapat data yang tidak seimbang, yaitu jumlah data pada kelas tertentu ada yang lebih sedikit atau lebih banyak dibandingkan pada kelas lainnya. Penelitian ini menggunakan teknik klasifikasi dengan menerapkan algoritma Naïve Bayes, $k$-Nearest Neighbor (k-NN) dan Neural Network guna mengetahui metode mana yang paling efektif dan memiliki kinerja terbaik. Naïve Bayes (Rahman, Rahmat, Fariqi, \& Adi, 2020) dan k-Nearest Neighbor (Devita, Herwanto, \& Wibawa, 2018) dipilih karena mudah diimplementasikan serta memberikan hasil baik dalam segala hal permasalahan. Sedangkan Neural Network dipilih karena dapat mengenali berbagai pola dengan baik serta dapat dikembangkan menjadi berbagai macam variasi sesuai dengan parameter atau masalah yang ada (Jayadianti, Cahyadi, Amri, \& Pitayandanu, 2020).

\section{State of the Art}

Chamidah, Santoni, dan Matondang (2020) dalam penelitiannya menggunakan teknik oversampling untuk mengatasi imbalance data. Oversampling diterapkan pada dataset hipertensi karena kelas hipertensi memiliki jumlah record yang sedikit bila dibandingkan dengan jumlah record untuk kelas tidak hipertensi. Evaluasi penggunaan oversampling dilakukan dengan mengimputasi missing value, melakukan oversampling, dan mentransformasi data ke dalam range yang sama, kemudian menerapkan algoritma klasifikasi. Hasilnya dengan menerapkan oversampling, Artificial Neural Network (ANN) paling baik dengan akurasi sebesar 0,91, disusul Decision Tree sebesar 0,86, dan Naïve Bayes sebesar 0,71. 
Prasetio dan Pratiwi (2015) dalam penelitian menggunakan lima dataset medis yang didapatkan dari UCI Machine Learning yaitu breast-cancer, liver-disorder, heart-disease, pima-diabetes dan vertebral column. Teknik begging digunakan untuk mengatasi imbalance data pada kelima dataset yang dipakai. Hasilnya Naïve Bayes memiliki akurasi paling tinggi di tiga dataset, sedangkan k-NN memiliki akurasi tertinggi di 2 dataset lainnya. Untuk algoritma C4.5 tidak ada yang paling unggul di dataset manapun.

Brown dan Mues (2012) dalam penelitiannya terkait imbalance data dengan mengusulkan class split dengan 6 persentase berbeda untuk komparasi 10 algoritma. Hasil penelitian tersebut adalah Gradient Boosting dan Random Forest paling baik dengan masing-masing unggul nilai AR (average rank) di dua split data. Namun untuk algoritma ANN dan k-NN dengan nilai $k=10$, bisa dikatakan ANN lebih unggul dari segi nilai AR di setiap split data daripada algoritma k-NN.

Religia, Nugroho, dan Hadikristanto (2021) menerapkan algoritma Random Forest untuk melakukan klasifikasi guna memperoleh model prediksi penerimaan pengajuan pinjaman dengan akurasi yang optimal. Pengujian yang telah dilakukan menghasilkan performa dari klasifikasi bank marketing dataset menggunakan algoritma Random Forest dengan akurasi sebesar 88,30\%, AUC (+) sebesar 0,500 dan AUC (-) sebesar 0,000. Penggunaan optimasi Bagging dan algoritma Genetika belum mampu meningkatkan performa dari algoritma Random Forest untuk klasifikasi bank marketing dataset.

Hairani, Saputro, dan Fadli (2020) mengusulkan algoritma k-means-SMOTE dibandingkan dengan beberapa algoritma klasifikasi, di antaranya adalah algoritma C4.5, Support Vector Machines (SVM), dan Naïve Bayes. Metode algoritma klasifikasi SVM memiliki akurasi $82 \%$ dan sensitivitas 77\% sedangkan metode klasifikasi Naïve Bayes menghasilkan nilai spesifikasi terbaik yaitu sebesar $89 \%$.

\section{Metode Penelitian}

Penelitian menerapkan data mining dengan metode Cross-Industry Standard Process for Data Mining (CRISP-DM) dengan enam tahapan (Larose \& Larose, 2014), tahapan tersebut di antaranya adalah:

\subsection{Business Understanding}

Business understanding merupakan fase memahami permasalahan imbalance data yang ada pada credit card fraud dataset.

\subsection{Data Understanding}

Data understanding merupakan fase pengumpulan data, mengembangkan analisis data serta melakukan evaluasi pada kualitas data. Penelitian ini menggunakan credit card fraud dataset yang didapat dari Kaggle.

\subsection{Data Preparation}

Data preparation merupakan proses untuk memperbaiki permasalahan yang terdapat dalam data dengan mengolah data dari credit card fraud dataset sebanyak 284.807 dengan 31 atribut. Proses ini dilakukan untuk membuat data lebih baik dan lebih layak sebelum diolah dengan algoritma. Pada tahapan ini juga meliputi beberapa proses diantaranya:

- Pemilihan data: Proses ini dilakukan dengan cara menyeleksi beberapa atribut yang akan digunakan sebagai pemodelan. Atribut yang digunakan yaitu atribut V1 sampai V28 dan class. Atribut class yang bernilai 0 jumlah data akan disamakan dengan jumlah data yang bernilai 1 .

- Pembersihan data: Data awalnya sejumlah 208.807 record dan masih ada missing value. Maka perlu dilakukan proses cleansing yaitu apabila ada missing value, maka data missing value akan dihilangkan, sehingga mengurangi jumlah data awal.

- Transformasi data: Tahapan ini menyederhanakan atribut pada data sehingga menghasilkan atribut yang baru.

Deployment: Proses ini melakukan dengan cara menyajikan hasil penelitian melalui makalah ini dan memberikan rekomendasi atau menggabungkan suatu keputusan dalam sistem terhadap objek penelitian agar dapat memberikan saran perbaikan untuk masa yang akan datang.

\subsection{Modeling}

Proses ini menerapkan teknik klasifikasi dari data mining dengan menggunakan algoritma Naïve Bayes, k-NN dan Neural Network.

\subsection{Evaluation}

Evaluasi dilakukan untuk mengetahui kinerja algoritma yang digunakan serta keefektifannya, sehingga diperoleh hasil prediksi yang paling bagus. Evaluasi didasarkan pada nilai akurasi dan nilai AUC pada setiap algoritma. Kemudian pada model algoritma dilakukan uji dengan $t$-test. Sehingga dapat 
dilakukan perbandingan performa. Perbandingan performa diketahui dengan cara membandingkan antara kondisi objek penelitian pertama dan kondisi objek pada penelitian kedua. Kemudian dapat disimpulkan apakah hasilnya signifikan atau tidak terhadap masing-masing algoritma.

\subsection{Deployment}

Proses ini melakukan dengan cara menyajikan hasil penelitian melalui makalah ini dan memberikan rekomendasi atau menggabungkan suatu keputusan dalam sistem terhadap objek penelitian agar dapat memberikan saran perbaikan untuk masa yang akan datang.

\section{Hasil dan Pembahasan}

Tabel 1 merupakan hasil evaluasi dari komparasi 3 algoritma yang digunakan dalam penelitian ini yang berisi nilai akurasi dari confusion matrix dan nilai AUC (area under the curve) yang didapat dari kurva ROC (receiver operating characteristic curve). Nilai AUC digunakan analisis klasifikasi untuk menentukan model yang paling baik dalam memprediksi data.

Tabel 1. Hasil perbandingan algoritma

\begin{tabular}{lccll}
\hline \multicolumn{1}{c}{ Algoritma } & Accuracy & AUC & \multicolumn{1}{c}{ Recall } & \multicolumn{1}{c}{ Precision } \\
\hline Naïve Bayes & $91,26 \%$ & 0,956 & $\begin{array}{l}\text { True negative: } 96,14 \% \\
\text { True positive: } 86,38 \%\end{array}$ & $\begin{array}{l}\text { Pred. negative: } 87,59 \% \\
\text { Pred. positive: } 95,72 \%\end{array}$ \\
k-NN & & & True negative: $65,04 \%$ & Pred. negative: $64,78 \%$ \\
& $64,84 \%$ & 0,684 & True positive: $64,63 \%$ & Pred. positive: $64,90 \%$ \\
Neural Network & & & True negative: $94,72 \%$ & Pred. negative: $92,64 \%$ \\
& $93,59 \%$ & 0,977 & True positive: $92,48 \%$ & Pred. positive: $94,59 \%$ \\
\hline
\end{tabular}

Pada Tabel 1, kinerja terbaik didasarkan pada akurasi dan AUC dihasilkan oleh algoritma Neural Network. Recall dan Precision kinerja terbaik dimiliki oleh algoritma Naïve Bayes dan Neural network. Sedangkan k-NN memiliki kinerja terburuk dari semua evaluasi (akurasi, recall, precision, dan AUC).

Tabel 2. Hasil $t$-test

\begin{tabular}{crrr} 
& Naïve Bayes & \multicolumn{1}{c}{ k-NN } & Neural Network \\
\hline Naïve Bayes & $0.913+/-0.029$ & $0.648+/-0.045$ & $0.936+/-0.030$ \\
k-NN & & 0.000 & 0.097 \\
Neural Network & & & 0.000 \\
\hline
\end{tabular}

Algortima yang lebih kecil dari nilai alpa 0,05 menunjukkan adanya perbedaan yang signifikan, karena dalam penelitian ini menggunakan nilai alpha 0,05. Asumsi dari nilai yang dihasilkan pada Tabel 2 adalah jika nilai $>0.05$ maka tidak ada perbedaan yang signifikan, sedangkan jika nilainya < 0.05 maka ada perbedaan yang signifikan. Dari

Tabel 2 menunjukkan hasil bahwa antara algoritma Naïve Bayes dan k-NN terdapat perbedaan yang signifikan karena memiliki nilai alpha $<0,05$. K-NN dan Neural Network juga mempunyai perbedaan yang signifikan. Sedangkan Naïve Bayes dan Neural Network tidak terdapat perbedaan yang signifikan karena memiliki nilai alpha $>0,05$.

Berdasarkan hasil evaluasi dan pengujian $t$-test, maka algoritma yang memiliki kinerja terbaik adalah algoritma Neural Network, sedangkan algoritma k-NN memiliki kinerja terburuk pada credit card fraud dataset. Penelitian ini mengkonfirmasi hasil penelitian Jayadianti, Cahyadi, Amri, dan Pitayandanu (2020) yang menyatakan bahwa algoritma Neural Network layak untuk dijadikan rekomendasi untuk penentuan algoritma. Walaupun penelitian Jayadianti, Cahyadi, Amri, dan Pitayandanu (2020) terkait prediksi, ternyata algoritma Neural Network pada penelitian ini juga cocok untuk teknik klasifikasi ketika data bersifat imbalance data.

\section{Kesimpulan}

Pada penelitian ini dilakukan perbandingan tiga algoritma (Naïve Bayes, k-NN dan Neural Network) untuk mengklasifikasi credit card fraud dataset. Data yang digunakan berjumlah 284.807. Data bersifat tidak seimbang. Sehingga dilakukan penyeimbangan data dengan cara menerapkan sample pada model klasifikasi yang dibuat.

Hasil pengujian menunjukkan bahwa algoritma Neural Network menghasilkan nilai akurasi tertinggi yaitu 93,59\% dan nilai AUC 0,977; Naïve Bayes dengan nilai akurasi 91,26\% dan nilai AUC 0,956; sedangkan k-NN menghasilkan nilai akurasi 64,84\% dan nilai AUC 0,709. Algoritma Naïve Bayes dapat: 1) Menangani dataset yang memiliki banyak atribut; 2) Jika terdapat nilai yang hilang maka bisa Analisis perbandingan algoritma Naïve Bayes, k-Nearest Neighbor dan Neural . . . h http://doi.org/10.26594/teknologi.v11i2.2393 Teknologi: Jurnal IImiah Sistem Informasi dengan lisensi CC BY NC SA. 
diabaikan; 3) Memiliki kelebihan dalam perhitungan; dan 3) Mudah dipahami. Algoritma k-NN memiliki karakteristik: 1) Sangat nonlinear; 2) Mudah dipahami; dan 3) Mudah diimplementasikan. Sedangkan algoritma Neural Network dapat memiliki suatu input data ke dalam suatu kategori tertentu yang sudah ditetapkan. Berdasarkan penelitian yang telah dilakukan maka dapat diambil kesimpulan bahwa algoritma Neural Network merupakan algoritma yang paling baik dibanding kedua algoritma lain yang dipakai untuk pemecahan masalah klasifikasi credit card fraud. Terdapat beberapa teknik untuk mengatasi data yang tidak seimbang, untuk penelitian selanjutnya diharapkan menggunakan metode lain untuk mengatasi data tidak seimbang sebelum menerapkan ke algoritma klasifikasi yang dipilih. Selain itu, membandingkan algoritma Naïve Bayes, k-NN dan Neural Network bisa dilakukan di jenis dataset lain untuk memperkuat dan membuktikan hasil temuan dalam penelitian ini.

\section{Referensi}

Brown, I., \& Mues, C. (2012). An experimental comparison of classification algorithms for imbalanced credit scoring data sets. Expert Systems with Applications, 39(3), 3446-3453.

Chamidah, N., Santoni, M. M., \& Matondang, N. (2020). Pengaruh Oversampling pada Klasifikasi Hipertensi dengan Algoritma Naïve Bayes, Decision Tree, dan Artificial Neural Network (ANN). Jurnal RESTI (Rekayasa Sistem dan Teknologi, 4(4), 635-641.

Devita, R. N., Herwanto, H. W., \& Wibawa, A. P. (2018). Perbandingan Kinerja Metode Naive Bayes dan K-Nearest Neighbor untuk Klasifikasi Artikel Berbahasa Indonesia. Jurnal Teknologi Informasi dan Ilmu Komputer, 5(4), 427-434.

Hairani, H., Saputro, K. E., \& Fadli, S. (2020). K-means-SMOTE untuk menangani ketidakseimbangan kelas dalam klasifikasi penyakit diabetes dengan C4.5, SVM, dan naive Bayes. Jurnal Teknologi dan Sistem Komputer, 8(2), 89-93.

Jayadianti, H., Cahyadi, T. A., Amri, N. A., \& Pitayandanu, M. F. (2020). Metode Komparasi Artificial Neural Network pada Prediksi Curah Hujan - Literature Review. Jurnal Tekno Insentif, 14(2), 48-53.

Karni, S. (2000). Auditing: Audit Khusus \& Audit Forensik dalam praktik. Jakarta: Universitas Indonesia.

Karyono, K. (2013). Forensic Fraud. Andi: Yogyakarta.

Khatri, S., Arora, A., \& Agrawal, A. P. (2020). Supervised Machine Learning Algorithms for Credit Card Fraud Detection: A Comparison. 10th International Conference on Cloud Computing, Data Science E Engineering (Confluence) (pp. 680-683). Noida, India: IEEE.

Larose, D. T., \& Larose, C. D. (2014). Discovering Knowledge in Data: An Introduction to Data Mining. John Wiley \& Sons.

Prasetio, R. T., \& Pratiwi, P. (2015). Penerapan Teknik Bagging pada Algoritma Klasifikasi untuk Mengatasi Ketidakseimbangan Kelas Dataset Medis. Jurnal Informatika, 2(2), 395-403.

Rahman, A., Rahmat, F., Fariqi, M. Y., \& Adi, S. (2020). Metode Naive Bayes untuk Menganalisis Akurasi Sentimen Komentar di Youtube. Jurnal EECCIS (electrics, electronics, communications, controls, informatics, systems), 14(1), 31-34.

Religia, Y., Nugroho, A., \& Hadikristanto, W. (2021). Analisis Perbandingan Algoritma Optimasi pada Random Forest untuk Klasifikasi Data Bank Marketing. Jurnal RESTI (Rekayasa Sistem dan Teknologi Informasi), 5(1), 187-192.

Shin, H., \& Cho, S. (2006). Response modeling with support vector machines. Expert Systems with Applications, 30(4), 746-760.

Shirodkar, N., Mandrekar, P., Mandrekar, R. S., Sakhalkar, R., Kumar, K. M., \& Aswale, S. (2020). Credit Card Fraud Detection Techniques - A Survey. International Conference on Emerging Trends in Information Technology and Engineering (ic-ETITE). Vellore, India: IEEE.

Zareapoor, M., Seeja, K. R., \& Alam, M. A. (2012). Analysis of Credit Card Fraud Detection Techniques: based on Certain Design Criteria. International Journal of Computer Applications, 52(3), 35-42. 